\title{
Totally versus planned conversion laparoscopic colectomy for colorectal cancers: the beginning of the learning curve
}

Mahmoud A. Abozeid ${ }^{\text {a*}}$, Ahmed A Abou-Zeid ${ }^{b}$, Hamdy Mohammed Hussein ${ }^{c}$, Mohammed Ahmed Omar

${ }^{a}$ Department of General Surgery, Faculty of Medicine, South Valley University, Qena, Egypt.

${ }^{\mathrm{b}}$ Department of General Surgery, Faculty of Medicine, Ain Shams University, Ain Shams, Egypt.

${ }^{\mathrm{c}}$ Department of General Surgery, Faculty of Medicine, Luxor University, Luxor, Egypt.

\begin{abstract}
Background: Colorectal cancers (CRC) are one of the major causes of cancer-related deaths worldwide. Laparoscopic colectomies have many advantages in short-term outcomes in comparison with open colectomies and recently have a long-term oncologic validation.
\end{abstract}

Objectives: This work aimed to compare the short- and medium-term outcomes of TLC and LPCC for CRC at the beginning of the learning curve of laparoscopic colectomy.

Materials and Methods: A randomized prospective study has been conducted from November 2018 to November 2020 on 30 patients with CRC were randomized to the total laparoscopic colectomy (TLC) group (15 patients) or laparoscopic-planned conversion colectomy LPCC group (15 patients). The primary outcomes were operative time, intra-operative blood loss, postoperative pain, hospital stay, and the secondary outcomes were early postoperative complications (anastomotic leak, pelvic nerve injuries), tumour recurrence, port-site metastasis, and hernia.

Results: There were statistically significant differences in the operative time $(244 \pm 40.9 \mathrm{~min}$ vs. 322 $\pm 57 \mathrm{~min} ; \mathrm{P}<0.001)$ and in the intra-operative blood loss $(240 \pm 118.3 \mathrm{cc}$ vs. $326.7 \pm 99.8 \mathrm{cc} ; \mathrm{P}<$ 0.039). There were no statistically significant differences in the post-operative pain, hospital stay, early postoperative complications, tumour recurrence, port-site metastasis, and hernia.

Conclusion: Laparoscopic planned conversion colectomy is a safe and feasible procedure in the management of selected patients with colorectal carcinoma especially at the beginning of the learning curve of laparoscopic colectomy with differences in the operative time and the intraoperative blood loss that need further studies to evaluate these differences and the possibility of being less significant.

Keywords: laparoscopic colectomy, total, planned conversion, learning curve.

\section{Introduction:}

Colorectal cancersare the third common cancers in the world, and approximately one-third of these cancers are in the rectum with a death rate about $50 \%$. Nearly 39220 new cases occurred in America in 2015 (Siegel et al., 2015).

Surgical resection is the main line of treatment for non-metastatic CRC (Schrag et al., 2000).

Conventional open colorectal surgery is now constantly being replaced by laparoscopic surgery due to improvement of the technologies and equipment, also, development of standard techniques has shared the widespread of laparoscopic colorectal surgery (LCS) (XinXiang Li and Ren-Jie Wang, 2015).

In comparison to open surgery, LCS has shortterm advantagesindecreased morbidity and hospitals stay with a fast return to normal activities (Guillou et al., 2005).

The treatment ofcolorectal cancers using the minimally invasive techniques is more performed through a LPCC, with extracorporeal anastomosis (ECA). Recently, the outcome of 
open and laparoscopic colectomy has been investigated, with no evidence of significant differences in morbidity, disease-free period, and overall survival (Allaix et al., 2016).

A TLC in which an intracorporeal anastomosis (ICA) is performed, considered more technically demanding and it was discussed much in literature(Allaix et al., 2016).

This study was conducted to compare the shortterm outcomes (operative time, intra-operative blood loss, postoperative pain, hospital stay, early postoperative complications (anastomotic leak, pelvic nerve injuries), and medium-term outcomes (tumour recurrence, port-site metastasis, and hernia) of TLC and LPCC for CRC.

\section{Materials and methods:}

This study consisted of all patients who underwent laparoscopic intervention for nonmetastatic colorectal cancers with curative intent admitted to the general surgery department, Qena University hospitals between November 2018 to November 2020 as a beginning of our experience in laparoscopic management of CRC patients.

Inclusion criteria: Non-metastatic colorectal cancer, fit for laparoscopy, not recurrent and not synchronous cancer. Exclusion criteria: T4 colorectal cancer, inoperable by CT \& MRI, recurrent colorectal cancers, intraoperative mishap leading to conversion to open surgery, contraindication to laparoscopy.

Patients who underwent TLC were case matched with those who had LPCC during the same period based on the following criteria: tumor location (colon or rectum), pathologic cancer stage (I, II, and III), type of procedure. demographics, comorbid factors, use of neoadjuvant chemoradiotherapy, perioperative outcomes, short-term outcomes (within 30 days after surgery), were compared between the patient groups.

A team of specialized colorectal surgeons performed all the operations in our series. We used a standard four-ports(Fig.1), medial-tolateral technique and standard surgical instrumentations used (Fig.2), dissection was done with a harmonic scalpel (Harmonic ACE, Ethicon Endo-Surgery, LLC, Guaynabo, Puerto Rico, USA).

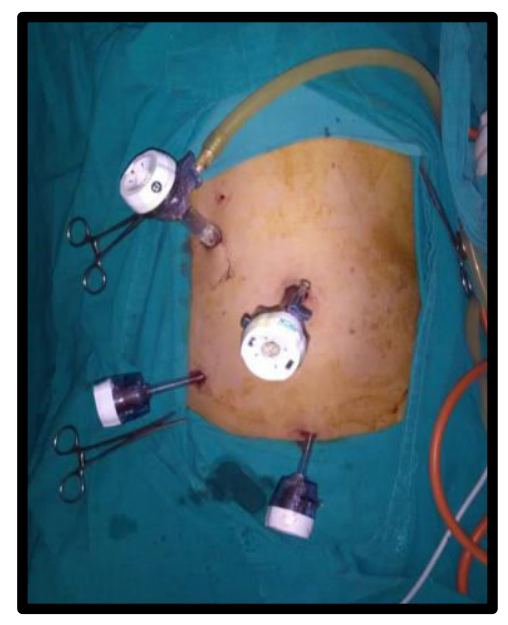

Fig.1: port position in left hemicolectomy

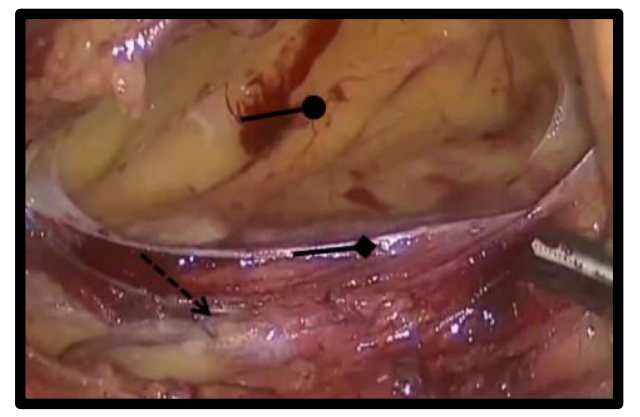

Fig.2: Identification of ureter in medial to lateral dissection (dotted arrow)

In the TLC group, the colon was mobilized and resected intracorporeally withEndo GIA linear stapler (Covidien Surgical, Mansfield, MA, USA) with a blue load. An iso-peristaltic anastomosis was performed using the same type of staplers after small enterotomies made for the anastomosis then closed by a double-layer running absorbable 3-0 suture or recto-anal anastomosis using (ETHICONTM Circular Stapler Ethicon Endo-Surgery (Europe) $\mathrm{GmbH}$ ) transanally. A mini-P fannenstiel incision was made at the site of the suprapubic trocar and used for specimen extraction. During LPCC, the colon was exteriorized through a mini laparotomy about $5 \mathrm{~cm}$ long at the site of the assistant port, and the colon was divided. We performed an end-to-end handsewn isoperistaltic anastomosis either ileocolic or colo-colic. Then 
the intestine was returned into the abdomen for the laparoscopically final check.

Total mesorectal excision was done for mid and low rectal tumours, whereas partial mesorectal excision was performed for upper rectal tumours.

The mesenteric defects closed. Drains were not routinely used. Nasogastric tubes used by the anaesthesiologists during anaesthesia were routinely removed immediately after the procedure. Postoperative care was standardized.

Complications are considered as any adverse event occurred within 30 days after the operation.

\section{Ethical Approval:}

The study protocol was approved by the Ethical Committee of Faculty of Medicine, South Valley University and written informed consent was taken from each patient.

\section{Statistical analysis:}

Data were verified, coded by the researcher, and analysed using IBM-SPSS v. 21.0.0 (SPSS Inc., Chicago, IL, USA). Continuous variables were expressed as mean \pm standard deviation and analysed with the Student $\mathrm{t}$ test. Categorical ones were expressed as percent value and analysed with Fischer test or Chi-square test, where appropriate. $\mathrm{P}<0.05$ were considered statistically significant.

\section{Results:}

Demographics and disease-related data for each cohort are shown in Table 1.

There were no statistically significant differences in terms of age, sex, surgical history, site of the tumour, and stage of disease according to American Joint Committee for Cancers (AJCC) TNM were similar too.

Table 1:Demographics and disease-related data

\begin{tabular}{|l|l|ll|l|}
\hline & $\begin{array}{l}\text { TLC } \\
n=15\end{array}$ & $\begin{array}{l}\text { LPCC } \\
n=15\end{array}$ & $\begin{array}{l}\text { P- } \\
\text { value }\end{array}$ \\
\hline Age(yrs.) & $51.7 \pm 9.2$ & 46.0 & \pm & 0.164 \\
\hline
\end{tabular}

\begin{tabular}{|l|l|l|l|}
\hline & & 12.5 & \\
\hline $\begin{array}{l}\text { Male/fema } \\
\text { le }\end{array}$ & $\begin{array}{l}6 / 9(40.0 / \\
60.0 \%)\end{array}$ & $\begin{array}{l}6 / 9(40.0 / \\
60.0 \%)\end{array}$ & 1.000 \\
\hline $\begin{array}{l}\text { abdominal } \\
\text { surgery }\end{array}$ & $3(20.0 \%)$ & $3(20.0 \%)$ & 1.000 \\
\hline $\begin{array}{l}\text { Tumour } \\
\text { site } \\
\text { colon } \\
\begin{array}{l}\text { Rectum } \\
\text { Rectosigm } \\
\text { oid }\end{array}\end{array}$ & $3(20.0 \%)$ & $4(26.7 \%)$ & 0.765 \\
\hline $\begin{array}{l}\text { Stage } \\
\text { I }\end{array}$ & $1(6.7 \%)$ & $2(13.3 \%)$ & 0.183 \\
II & $5(33.3 \%)$ & $9(60.0 \%)$ & 0.183 \\
III & $9(60.0 \%)$ & $4(26.7 \%)$ & 0.183 \\
\hline
\end{tabular}

TLC: Total Laparoscopic colectomy; LPCC: Laparoscopic Planned Conversion Colectomy

Short-term outcomes are listed in Table 2. No conversion to open surgery was recorded. Both groups achieved an adequate.

Table 2:Short- and medium-term outcome

\begin{tabular}{|l|l|l|l|}
\hline & $\begin{array}{l}\text { TLC } \\
\mathrm{n}=15\end{array}$ & $\begin{array}{l}\text { LPCC } \\
\mathrm{n}=15\end{array}$ & $\begin{array}{l}\text { P- } \\
\text { value }\end{array}$ \\
\hline $\begin{array}{l}\text { Operative time } \\
(\mathrm{min})\end{array}$ & $244 \pm 40.9$ & $322 \pm 57$ & $\begin{array}{l}<0.00 \\
1\end{array}$ \\
\hline $\begin{array}{l}\text { Blood loss } \\
(\mathrm{ml})\end{array}$ & $240 \pm 118$ & $327 \pm 99.8$ & 0.039 \\
\hline $\begin{array}{l}\text { Hospital stays } \\
\text { (day) }\end{array}$ & $7.8 \pm 1.1$ & $8.4 \pm 1.9$ & 0.547 \\
\hline $\begin{array}{l}\text { Earlycomplica } \\
\text { tions } \\
\text { Ureteric injury } \\
\text { Ileus }\end{array}$ & $1(6.7 \%)$ & 0 & 0.368 \\
Anastomotic & $4(26.7 \%)$ & $4(26.7 \%)$ & 1.000 \\
\hline
\end{tabular}




\begin{tabular}{|l|l|l|l|}
\hline leak & $1(6.7 \%)$ & $1(6.7 \%)$ & 1.000 \\
Bleeding & $1(6.7 \%)$ & $1(6.7 \%)$ & 1.000 \\
Nerve injury & 0 & $1(6.7 \%)$ & 0.309 \\
$\begin{array}{l}\text { Chest } \\
\text { infection } \\
\text { SSI }\end{array}$ & $2(13.3 \%)$ & $2(13.3 \%)$ & 1.000 \\
$\begin{array}{l}\text { Stoma } \\
\text { complication }\end{array}$ & $2(13.3 \%)$ & $3(20 \%)$ & 0.624 \\
\hline $\begin{array}{l}\text { Late } \\
\text { complications } \\
\text { hernia }\end{array}$ & $1(6.7 \%)$ & $2(13.3 \%)$ & 0.543 \\
\hline $\begin{array}{l}\text { TLC: Total Laparoscopic colectomy; } \\
\text { LPCC:Laparoscopic Planned Conversion } \\
\text { Colectomy }\end{array}$ & $2(13.3 \%)$ & 0.543 \\
\hline
\end{tabular}

Median operative time $(244.00 \pm 40.85$ min vs $322.00 \pm 56.97 \mathrm{~min} ; \mathrm{P}<0.001)$ and estimated blood loss $(240.0 \pm 118.32 \mathrm{ml}$ vs $326.67 \pm 99.76$ $\mathrm{ml}$; 0.039) were statistically comparable in both groups.

1 case of anastomotic leakage was recorded in each group, managed conservatively.

Out of 6 cases (40\%) in TLC group and 9 cases $(60 \%)$ in LPCC group who had stomas only 1 case in TLC group and 2 cases in LPCC group had complications in the form of skin maceration managed conservatively in 2 cases and 1 case of stomal ischemia managed conservatively.

\section{Discussion:}

In comparison to open colectomies short-term values of LCS are well known and include decreased blood loss, decreased postoperative pain, early regain of intestinal functions, and shorter hospital stays(Phillips et al., 2016).

LCS was proven to have better oncological results in comparison with conventional open surgery, overcoming the early fears about portsite metastases and oncologic safety of resections (Jayne et al., 2010).
Laparoscopic surgery of the colon has essentially two variants, LPCC and TLC, which both use the same dissection techniques. But in LPCC both vascular control and intestine mobilization are performed by laparoscopy, but the resection and the anastomosis are done extracorporeal. While, in TLC, all the surgical steps are done intracorporeally, and so, it can be considered as a total laparoscopic technique.

Recently, the oncologic radicality standards including high ligation of the central arterial supply, proper proximal and distal resection margins, proper lymph nodes dissection, and the no-touch technique that prevents manipulation and perforation of the tumour(Young-Fadok et al., 2007).

Although operative time is a poor indicator for the learning curve in laparoscopic colorectal surgery (Barrie et al, 2014), but our early experience in laparoscopic colorectal cancer surgery may explain the long operative time in both study groups compared with other studies, as our operative time in TLC group is statistically lower than LPCC group is ranging.

In comparison to the study made by Roscio et al., 2012, the duration of the operation in the laparoscopic-conversion group was longer than the laparoscopic-successful group but not statistically significant. This variation is affected in our study by surgeon experience in the early cases in the study, while the time gradually decreased with gaining more experience. However, some different results were due to the different anastomosis techniques. However, we performed only hand sewn side-to-side ECA.

In our study, the amount of blood loss during surgery in the TLC group is statistically lower than LPCC group. In comparison to other studies made by Roscio et al., 2012, intraoperative blood loss was greater in a laparoscopic-conversion group than in a laparoscopic-successful group but not statistically significant. More blood loss in the conversion group usually due to wider incisions and the use of combined sharp and blunt dissection with more blood loss while in the laparoscopic group more precise dissection is done with less blood loss. 
Less blood loss in laparoscopic surgery may be due to the use of modern energy devices during laparoscopic surgery that optimize precise tissue cutting and coagulation and decrease blood loss(Allaix et al., 2017).

The results of our work are comparable in terms of morbidity and mortality with those of other authors who have studied this topic.

The authors believe that an ICA gives us a direct vision of the entire surgical field. This is important for proper orientation of the anastomotic line, avoiding twisting of the bowel and thus abolishing the errors in performing the anastomosis.

In TLC the mesentery is closed under vision, thus avoiding excessive tractions of the bowel and tissues through the mini-laparotomy,and lowering the risk of ischemia for anastomosis.

In our study, the mean of hospital stay among in TLC group is shorter than the LPCC group with no statistical difference. In comparison to a study made by steven et al., 2017. The more hospital stays in the conversion group is mainly due to slightly longer postoperative recovery period where longer time for intestinal sound recovery, more analgesia required to overcome pain due to longer abdominal incisions.

Also, in cases where wound infection occurred, more time they spent in the hospital increase the hospital stay statistics and may need readmission. All this occurred more in the conversion group rather than the laparoscopic group where wound infection is less.

\section{Conclusion:}

Laparoscopic colorectal resection has less blood loss, less postoperative pain, early ambulance, and shorter hospital stay. On the other hand, planned conversion strategy in laparoscopic colorectal resection does not adversely affect short-term outcomes or medium-term survival in patients with non-metastatic colorectal cancers. And especially can be performed at the beginning of the learning curve of laparoscopic colectomy omitting the need for stapling devices but with longer operative time and more blood loss that requires more studies to evaluate these parameters and feasibility of this procedure.

\section{References:}

Allaix M, Arezzo A, Giraudo G, Arolfo S, Mistrangelo $M$ (2017). The Thunderbeat and Other Energy Devices in Laparoscopic Colorectal Resections: Analysis of Outcomes and Costs.' Journal of Laparo-endoscopic and Advanced Surgical Techniques, 27(12): 1225-1229.

\section{Allaix M, Furnée E, Mistrangelo M, Arezzo} A, orino M(2016). Conversion of laparoscopic colorectal resection for cancer: What is the impact on short-term outcomes and survival?World J. Gastroenterol, 22(37): 8304-8313.

Barrie J, Jayne D, Wright j, Carolyn J, Fiona $\mathbf{J}(\mathbf{2 0 1 4})$. Attaining Surgical Competency and Its Implications in Surgical Clinical Trial Design: A Systematic Review of the Learning Curve in Laparoscopic and Robot Assisted Laparoscopic Colorectal Cancer Surgery. Ann. Surg. Oncol, (21):829-840.

Roscio F, Bertoglio C, De Luca A, Frattini P, Scandroglio I (2012). Totally laparoscopic versus laparoscopic assisted right colectomy for cancer. International Journal of Surgery 10: $290 \mathrm{e} 295$

Guillou P, Quirke P, Thorpe H, Walker J, Jayne $\mathbf{D}(\mathbf{2 0 0 5})$. Short-term endpoints of conventional versus laparoscopic-assisted surgery in patients with colorectal cancer (MRC CLASICC trial): Multicentre, randomised controlled trial. Lancet; 365:1718.

Jayne D, Thorpe H, Copeland J, Quirke P, Brown J(2010). Five-year follow-up of the Medical Research Council CLASICC trial of laparoscopically assisted versus open surgery for colorectal cancer. Br. J. Surg, 97:1638.

Phillips E, Franklin M, Carroll B, Fallas M, Ramos R(2016). Rosenthal D. Laparoscopic colectomy. Annals of Surgery, 216:703. 
Schrag D, Cramer L, Bach P, Cohen A, Warren J(2000). Influence of hospital procedure volume on outcomes following surgery for colon Cancer. JAMA;284(23):3028e3035.

Siegel R, Sahar L, Portier K, Ward E, Jemal $\mathbf{A}(\mathbf{2 0 1 5})$. Cancer death rates in US congressional districts. CA, Cancer, J. Clin., 65 (5), 339e344.

Steven G, Moloo H, and Mamazza J(2017). Laparoscopic resections for colorectal cancer:doesconversion survival? Surg. Endosc.;18:732-735.

Wells K, Hawkins A, Krishnamurthy D, Dharmarajan S, Glasgow S(2017). Omission of adjuvant chemotherapyis associated with increased mortality in patients with T3N0 colon cancer with inadequate lymph node harvest. Dis Colon Rectum; 60:15-21.

Xin-Xiang Li and Ren-Jie Wang (2015). Core value of laparoscopic colorectal surgery. World J. Gastrointest. Endosc; 7(18): 12951299.

Young-Fadok T, Fanelli R, Price $\mathbf{R}$, and Earle D (2007). Laparoscopic resection of curable colon and rectal cancer: an evidencebased review.SurgEndosc; 21:1063e8. 